\title{
PENGARUH E-SERVICE QUALITY DAN E-TRUST TERHADAP KEPUASAN NASABAH PENGGUNA BNI MOBILE BANKING MELALUI CITRA BANK SEBAGAI VARIABEL INTERVENING (STUDI KASUS PADA NASABAH PENGGUNA BNI MOBILE BANKING DI KOTA DEPOK)
}

\author{
Sri Nawangasari ${ }^{1}$ dan Nadea Dwirahma Putri ${ }^{2}$ \\ Program Studi Managemen, Fakultas Ekonomi, Universitas Gunadarma ${ }^{1,2}$ \\ Jalan Margonda Raya 100 Pondok Cina, Depok, Jawa Barat \\ Sur-el : snsari@staff.gunadarma.ac.id', nadearahma@gmail.com²
}

\begin{abstract}
This study aims to determine the effect of e-service quality and e-trust on customer satisfaction of BNI Mobile banking users through the image of the bank as an intervening variable. Data used in this study are primary data, data collection through questionnaires with a total sample of 185 respondents who are "BNI Mobile banking" customers use a purposive sampling technique. Analysis of the data used is descriptive analysis and path analysis. The results showed that: The e-service quality variable directly affected the customer satisfaction variable; The e-trust variable directly influences the customer satisfaction variable; e-service quality variables affect the image of the bank, e-trust variables affect the image of the bank, and the image of the bank affect customer satisfaction. Thus, BNI Bank should continue to improve service quality and trust in the Bank so that customers feel satisfied so that the bank's reputation is better.
\end{abstract}

Keywords: E-Service Quality; E-trust; Bank Image; Customer Satisfaction

\begin{abstract}
Abstrak : Penelitian ini bertujuan untuk mengetahui pengaruh e-service quality dan e-trust terhadap kepuasan nasabah pengguna BNI Mobile banking melalui citra bank sebagai variabel intervening. Data yang digunakan dalam penelitian ini adalah data primer, pengumpulan data melalui kuesioner dengan jumlah sampel sebanyak 185 responden yang merupakan nasabah "Pengguna BNI Mobile banking" menggunakan teknik purposive sampling. Analisis data yang digunakan adalah analisis deskriptif dan analisis jalur (Path Analysis). Hasil penelitian menunjukkan bahwa: Variabel e-service quality berpengaruh langsung terhadap variabel kepuasan nasabah; Variabel e-trust berpengaruh langsung terhadap variabel kepuasan nasabah; variabel e-service quality berpengaruh terhadap citra bank, variabel e-trust berpengaruh terhadap citra bank, dan citra bank berpengaruh terhadap kepuasan nasabah. Dengan demikian, sebaiknya Bank BNI terus meningkatkan kualitas layanan dan kepercayaan terhadap Bank sehingga nasabah merasa puas sehingga reputasi bank menjadi lebih baik.
\end{abstract}

Kata kunci: E-Service Quality, E-trust, Citra Bank, Kepuasan Nasabah

\section{PENDAHULUAN}

Pada saat ini perkembangan Teknologi Informasi (TI) sudah semakin pesat dan canggih. Ditandai dengan kemajuan Teknologi Informasi di berbagai bidang salah satunya di bidang bisnis, yakni perbankan. Sudah sangat jelas peran teknologi informasi dalam bidang perbankan mustahil untuk dipisahkan, karena hampir seluruh mekanisme pelaksanaan dan pemrosesan data hanya dapat diselesaikan dengan teknologi informasi.

Salah satu bentuk layanan dari perbankan yang memanfaatkan kemajuan teknologi informasi adalah mobile banking. Mobile banking adalah fasilitas layanan perbankan berupa aplikasi yang memudahkan nasabah 
untuk bertransaksi langsung melalui smartphone. Dengan adanya berbagai kemudahan fasilitas layanan mobile banking diharapkan nasabah akan memperoleh kepuasan dalam menggunakan berbagai macam produk dan jasa yang diberikan oleh pihak bank [1-4]. Setiap bank dituntut untuk menciptakan keunggulan yang berkesinambungan, agar dapat memenangkan persaingan di dunia perbankan.

Bank BNI adalah salah satu bank yang menyediakan fasilitas layanan mobile banking yang unggul. BNI Mobile banking memberikan layanan seperti, transaksi informasi saldo, transfer, pembelian pulsa, dan lain-lain dengan aman, mudah, dan cepat, serta dapat di akses di mana saja selama 24 jam. Hanya dengan mengakses melalui smartphone, sehingga nasabah tidak perlu keluar rumah untuk bertransaksi pada mesin ATM.

Visi Bank BNI adalah menjadi lembaga keuangan yang unggul dalam layanan dan kinerja. Dengan salah satu misinya yaitu memberikan layanan prima dan solusi yang bernilai tambah kepada seluruh nasabah dan selaku mitra pilihan utama. Dengan visi dan misi tersebut Bank BNI banyak mendapatkan penghargaan.

Dari berbagai penghargaan yang di dapat oleh Bank BNI tersebut, menandakan bahwa banyak nasabah yang puas dan percaya terhadap pelayanan dari Bank BNI. Strategi bisnis Bank BNI pun fokus pada segmen bisnis digital, sehingga tidak salah banyak masyarakat yang setia dan memilih Bank BNI.

Kualitas layanan merupakan kunci dari ukuran kepuasan nasabah. Jika kinerja gagal memenuhi ekspektasi, konsumen akan tidak puas. Bank juga harus membentuk sikap positif yang dapat meningkatkan kepercayaan nasabah, bahwa mobile banking aman untuk digunakan. Citra bank yang baik juga akan mendapatkan kesan yang baik pula dari nasabah, serta akan berdampak pada kemajuan perusahaan[5-8].

E-service quality dan E-trust merupakan salah satu strategi yang dilakukan oleh bank agar nasabah merasa puas, selain itu juga ada faktor yaitu citra bank yang dapat menjadi perantara artinya pengaruhnya tidak kelihatan tapi mempengaruhi kepuasan nasabah, oleh karena itu penting bagi Bank BNI untuk tetap menjaga dan meningkatkan citra bank, e-service quality, dan e-trust untuk menjaga tingkat kepuasan nasabah pengguna BNI Mobile banking[9-11].

Berdasarkan hasil riset yang dilakukan oleh Warta Ekonomi dengan tema Best Banking Brand Award 2017, PT Bank BNI mendapatkan peringkat pertama dalam penilaian Good Financial Performance untuk kategori bank pemerintahan dan peringkat pertama dalam penilaian Consumer Satisfaction untuk kategori Great Customer Service Bank. Berikut tabel 1 peringkat Best Banking Brand Award 2017:

Tabel 1. Best Banking Brand Award 2017

\begin{tabular}{lll}
\hline $\begin{array}{c}\text { Good Financial } \\
\text { Performance } \\
\text { (Kategori Bank } \\
\text { Pemerintah) }\end{array}$ & $\begin{array}{c}\text { Consumer } \\
\text { Satisfaction } \\
\text { (Kategori Great } \\
\text { Customer Service } \\
\text { Bank) }\end{array}$ \\
\hline 1. PT Bank Negara & 1. $\begin{array}{l}\text { PT Bank Negara } \\
\text { Indonesia }\end{array}$ & Indonesia \\
2. PT Bank Rakyat & 2. $\begin{array}{l}\text { PT Bank CIMB } \\
\text { Indonesia }\end{array}$ & Niaga \\
3. PT Bank Tabungan & 3. $\begin{array}{l}\text { PT Bank Rakyat } \\
\text { Negara }\end{array}$ & Indonesia \\
\hline
\end{tabular}


Bank BNI juga mendapatkan penghargaan Top IT Implementation on Banking Sector 2017, The Best Banking Technology Pioneer In Indonesia 2017, The Best Bank in Digital Services, dan lain-lain. Berikut tabel 2 peringkat The Best Bank in Digital Services:

Tabel 2. The Best Bank In Digital Service

\begin{tabular}{ll}
\hline $\begin{array}{l}\text { The Best Bank in Digital Services (Kategori } \\
\text { Aset Rp100T dan di atas Rp100T) }\end{array}$ \\
\hline 1. & PT Bank Negara Indonesia \\
2. & PT Bank Rakyat Indonesia \\
3. & PT Bank Danamon \\
\hline
\end{tabular}

Dari berbagai penghargaan yang didapat oleh Bank BNI tersebut, menandakan bahwa banyak nasabah yang puas dan percaya terhadap pelayanan dari Bank BNI. Diikuti dengan penerapan dan pelopor teknologi informasi terbaik dalam sektor perbankan mengakibatkan meningkatnya jumlah pengguna BNI Mobile banking. Strategi bisnis Bank BNI pun fokus pada segmen bisnis digital, sehingga banyak masyarakat yang setia dan memilih Bank BNI.

Untuk menghindari adanya pembahasan di luar konteks dari setiap variabel terkait di dalam penelitian ini, maka peneliti menentukan batasan-batasan masalah sebagai berikut:

1. Studi kasus pada Nasabah Pengguna BNI Mobile banking di Kota Depok.

2. Banyak faktor yang berpengaruh terhadap kepuasan nasabah, namun penelitian ini hanya akan berfokus pada 3 variabel independen yaitu e-service quality, e-trust, dan citra bank.

3. Data yang diolah dalam penelitian ini adalah data primer yang diperoleh dari penyebaran kuesioner online.
Hasil penelitian ini diharapkan dapat menjadi masukan dan bahan pertimbangan yang bermanfaat bagi PT. Bank Negara Indonesia (BNI) dalam menjalankan strategi pemasaran yang baik, khususnya dalam meningkatkan kepuasan nasabah yang diharapkan dapat terus menggunakan fitur layanan BNI Mobile banking.

Penelitian ini diharapkan dapat digunakan sebagai bahan pertimbangan bagi masyarakat (nasabah) dalam menentukan tingkat kepuasan terhadap suatu layanan jasa bank dengan mempertimbangkan aspek e-service quality, etrust, dan citra bank yang tersedia.

\section{METODOLOGI PENELITIAN}

\subsection{E-Service Quality}

E-Service Quallity adalah seberapa jauh sebuah website atau aplikasi memfasilitasi pembelanjaan yang efektif dan efisien, pembelian, dan penyampaian jasa atau produk[12-14]. Kesimpulannya e-Servqual adalah metode untuk mengukur kepuasan pelanggan terhadap penyedia layanan berbasis Internet meliputi pembelanjaan, dan penyampaian jasa atau produk.

\subsection{E-trust}

Kepercayaan pada layanan jasa berbasis internet disebut elektronik trust (e-trust). E-trust didefinisikan sebagai kepercayaan terhadap harapan dalam situasi risiko online bahwa kerentanan tidak akan dieksploitasi [15]. Suatu transaksi bisnis antara dua pihak atau lebih akan terjadi apabila masing-masing saling mempercayai. 


\subsection{Citra Bank}

Citra adalah persepsi masyarakat terhadap perusahaan atau produknya [16]. Citra suatu perusahaan yang meliputi nama baik perusahaan, reputasi ataupun keahliannya merupakan faktor yang sering mempengaruhi keputusan konsumen dari sektor jasa dibandingkan sektor produk [17].

\subsection{Kepuasan Nasabah}

Kepuasan konsumen adalah hasil akumulasi dari konsumen dalam menggunakan produk dan jasa[18]. Kepuasan nasabah sebagai hasil penilaian nasabah terhadap apa yang diharapkannya dengan membeli dan mengonsumsi suatu produk/jasa. Kepuasan nasabah hanya dapat tercapai dengan pemberian pelayanan yang berkualitas kepada nasabah tertera dalam gambar 1.

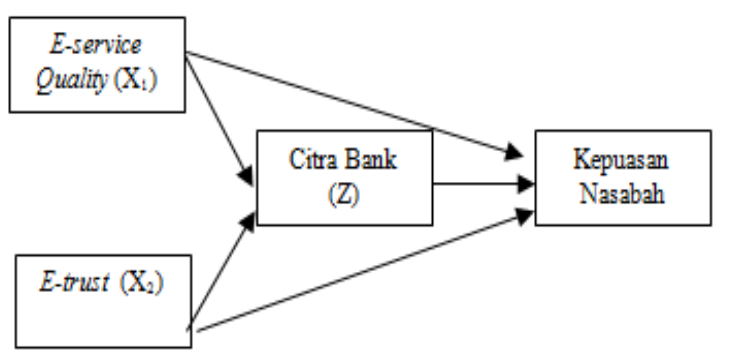

Gambar 1. Kerangka pemikiran

Keterangan gambar 1:

$\mathrm{H} 1=$ E-service quality berpengaruh terhadap kepuasan nasabah pengguna BNI Mobile banking

$\mathrm{H} 2=$ E-trust berpengaruh terhadap kepuasan nasabah pengguna BNI Mobile banking

$\mathrm{H} 3=$ E-service quality berpengaruh terhadap citra bank

H4= E-trust berpengaruh terhadap citra bank

H5= Citra bank berpengaruh terhadap kepuasan nasabah pengguna BNI Mobile banking
Subjek dalam penelitian ini adalah nasabah pengguna BNI Mobile banking di Kota Depok yang pernah melakukan transaksi dengan menggunakan BNI Mobile banking. Sedangkan objek dalam penelitian ini adalah BNI Mobile banking. Populasi dalam penelitian ini adalah seluruh nasabah pengguna BNI Mobile banking di Kota Depok. Penelitian ini akan menggunakan teknik pengambilan sampel non probability sampling, yaitu teknik pengambilan sampel yang tidak memberi peluang/kesempatan yang sama bagi setiap unsur atau anggota populasi untuk dipilih menjadi sampel. Dalam penelitian ini, pertimbangan yang dimaksud adalah sebagai berikut:

1. Responden merupakan nasabah Bank BNI.

2. Responden merupakan nasabah pengguna BNI Mobile banking.

3. Responden pernah melakukan transaksi dengan menggunakan BNI Mobile banking .

Pada penelitian ini jumlah sampel yang digunakan adalah 185 responden yang dirasakan sudah cukup untuk mewakili populasi. Data dikumpulkan dengan menggunakan kuesioner yang kemudian dianalisis dengan analisis deskriptif dan analisis jalur (path analysis). Variabel bebas dalam penelitian ini adalah e-service quality dan e-trust, variabel terikatnya kepuasan nasabah dan variabel interveningnya citra bank.

Analisis Jalur mendefinisikan analisis jalur sebagai "Model perluasan regresi yang digunakan untuk menguji keselarasan matriks korelasi dengan dua atau lebih model hubungan sebab akibat yang dibandingkan oleh peneliti [19]. Regresi dikenakan pada masing-masing variabel dalam suatu model sebagai variabel tergantung (pemberi respon) sedang yang lain sebagai penyebab. Pembobotan regresi 
diprediksikan dalam suatu model yang dibandingkan dengan matriks korelasi yang diobservasi untuk semua variabel dan dilakukan juga penghitungan uji keselarasan statistik [19]. Dalam melakukan analisis data, penulis menggunakan analisis deskriptif yang membandingkan data yang ada dengan berbagai teori yang mendukung dan bersifat menjelaskan atau menguraikan dan memakai bantuan SPSS (Statistics product and Service Solution) versi 16,0. Untuk melihat pengaruh fasilitas dan disversifikasi produk terhadap kepuasan konsumen melalui kualitas pelayanan sebagai variabel intervening maka digunakan Analisis Jalur (path analysis) sebagai berikut :

a. Persamaan $1: Z=$ PZ.X1 + PZ.X2 $+\varepsilon$

b. Persamaan 2 : Y = PY.X1 + PY.X2 + PY.Z $+\varepsilon$

Keterangan persamaan 1-2:

$\mathrm{X} 1 \ldots \mathrm{Y} 1$

$\mathrm{X} 1$ = E-Service Quality

$\mathrm{X} 2=$ E-trust

$\mathrm{Z}=$ Citra Bank

$\mathrm{Y}=$ Kepuasan Nasabah

$\varepsilon=$ Standar error

\section{HASIL DAN PEMBAHASAN}

\subsection{Uji Validitas}

Untuk mengetahui valid suatu variabel, dilakukan dengan membandingkan $r$ hitung dan $r$ tabel atau dapat dilihat dari nilai probabilitas (pvalue). Data dikatakan valid jika $r$ hitung $>\mathrm{r}$ tabel atau $\mathrm{p}$ value $<5 \%$ [20]. Hasil uji Validitas dapat diketahui bahwa seluruh item pertanyaan dari Variabel E-Service Qualty, E-trust, Citra Bank, dan Kepuasan nasabah valid karena jika $r$ hitung $>r$ table.

\subsection{Uji Reliabilitas}

Uji reliabilitas dilakukan terhadap item pertanyaan yang dinyatakan valid. Suatu variabel dikatakan reliabel atau handal jika jawaban terhadap pertanyaan selalu konsisten. Pengujian reliabilitas dilakukan dengan teknik Cronbach's Alpha $(\alpha)$ dengan jumlah sampel 185 responden Suatu instrument penelitian dinyatakan reliable apabila nilai alpha > 0,60 [20]. Berikut tabel 3 Hasil Uji Reliabilitas:

Tabel 3. Hasil Uji Reliabilitas

\begin{tabular}{lcc}
\hline \multicolumn{1}{c}{ Variable } & $\begin{array}{c}\text { Koofisien } \\
\text { Alpha }\end{array}$ & Keterangan \\
\hline $\begin{array}{l}\text { E- Service } \\
\text { Quality }\end{array}$ & 0,837 & Reliabel \\
E- Trust & 0,800 & Reliabel \\
Citra Bank & 0,887 & Reliabel \\
Kepuasan & 0,811 & Reliabel \\
Nasabah & & \\
\hline
\end{tabular}

Berdasarkan Tabel 3 diatas, dapat diketahui bahwa instrument penelitian memiliki nilai koefisien alpha > 0,60, maka dapat disimpulkan bahwa instrument penelitian tersebut dinyatakan reliabel.

\subsection{Hasil Analisis Jalur (Path Analysis)}

Path analysis jalur pada penelitian ini dapat dilihat pada gambar 2 .

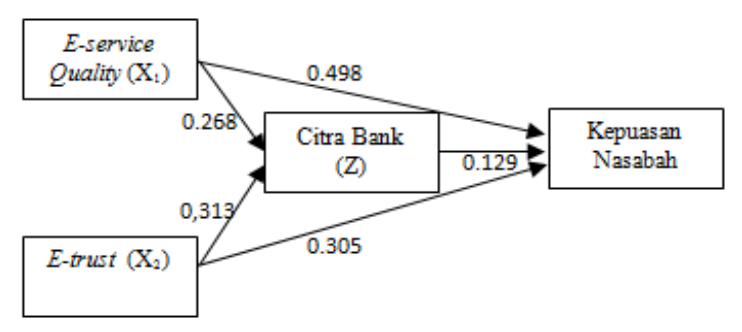

Gambar 2. Path analysis

Persamaan untuk gambar 2:

Persamaan 1: $Z=0,268 X 1+0,313 X 2+€$

Persamaan 2: $\mathrm{Y}=0,498 \mathrm{X} 1+0,305 \mathrm{X} 2+0,129 \mathrm{Z}+€$

Hasil analisis jalur pada penelitian ini dapat dilihat pada tabel 4. 
Tabel 4. Hasil Analisis Jalur

\begin{tabular}{ccccc}
\hline Variabel & $\begin{array}{c}\text { Pengaruh } \\
\text { Langsung } \\
\text { (Beta) }\end{array}$ & $\begin{array}{c}\text { Pengaruh } \\
\text { Tidak langsung }\end{array}$ & $\begin{array}{c}\text { Pengaruh } \\
\text { Total }\end{array}$ & p-value \\
\hline $\begin{array}{c}\text { E-Service Quality }\left(\mathrm{X}_{1}\right) \rightarrow \\
\text { Kepuasan Nasabah }(\mathrm{Y})\end{array}$ & 0,498 & 0,02167 & 0,51967 & 0,000 \\
$\quad \begin{array}{c}\text { E-trust }\left(\mathrm{X}_{2}\right) \rightarrow \\
\text { Kepuasan Nasabah }(\mathrm{Y})\end{array}$ & 0,305 & 0,01689 & 0,32189 & 0,000 \\
$\begin{array}{c}\text { E-Service Quality }\left(\mathrm{X}_{1}\right) \rightarrow \\
\quad \text { Citra Bank }(\mathrm{Z})\end{array}$ & 0,268 & - & 0,268 & 0,046 \\
$\begin{array}{c}\text { E-trust }\left(\mathrm{X}_{2}\right) \rightarrow \text { Citra Bank } \\
(\mathrm{Z})\end{array}$ & 0,313 & - & 0,313 & 0,008 \\
$\begin{array}{c}\text { Citra Bank }(\mathrm{Z}) \rightarrow \\
\text { Kepuasan Nasabah }\end{array}$ & 0,129 & - & 0,129 & 0,012 \\
\hline
\end{tabular}

\subsection{Pengaruh E-Service Quality Terhadap Kepuasan Nasabah}

Tabel 4 menunjukkan e-service quality berpengaruh langsung terhadap Kepuasan nasabah. Pengaruh tersebut ditunjukkan dengan nilai koefisien sebesar 0,498 H1 yang menyatakan bahwa e-service quality berpengaruh terhadap Kepuasan nasabah dapat diterima. Hal ini dibuktikan melalui hasil uji dimana nilai probabilitas (p-value) sebesar 0,000 kurang dari nilai signifikansi 0,05 menunjukkan hasil yang signifikan. Kepuasan nasabah akan meningkat apabila indikator yang terdapat dalam e-service quality yaitu, information, ease of use, website design, reliability, dan security/privacy berkualitas baik. Pengaruh e-service quality terhadap kepuasan nasabah lebih besar jika melalui citra bank dengan nilai pengaruh tidak langsung sebesar 0,02167 dengan total pengaruh sebesar 0,51967 yang artinya ketika diiringi oleh citra bank yang baik maka kepuasan nasabah akan semakin meningkat.

\subsection{Pengaruh E-trust Terhadap Kepuasan Nasabah}

Tabel 4 menunjukkan e-trust berpengaruh langsung terhadap Kepuasan nasabah. Pengaruh tersebut ditunjukkan dengan nilai koefisien sebesar 0,305 H2 yang menyatakan bahwa e-trust berpengaruh terhadap Kepuasan nasabah dapat diterima. Hal ini dibuktikan melalui hasil uji dimana nilai probabilitas (p-value) sebesar 0,000 kurang dari nilai signifikansi 0,05 menunjukkan hasil yang signifikan. Kepuasan nasabah akan semakin meningkat apabila indikator e-trust yaitu ability, integrity, dan benevolence meningkat. Seperti peningkatan layanan yang baik, aman, jujur, dan akurat. Pengaruh $e$-trust terhadap kepuasan nasabah lebih besar jika melalui citra bank dengan nilai pengaruh tidak langsung sebesar 0,01689 dengan total pengaruh sebesar 0,32189 yang artinya ketika diiringi oleh citra bank yang baik maka kepuasan nasabah akan semakin meningkat.

\subsection{Pengaruh E-Service Quality Terhadap Citra Bank}

Tabel 4 menunjukkan e-service quality berpengaruh langsung terhadap Citra Bank. Pengaruh tersebut ditunjukkan dengan nilai koefisien sebesar 0,268 . $\mathrm{H} 3$ yang menyatakan bahwa e-service quality berpengaruh terhadap citra bank dapat diterima. Hal ini dibuktikan melalui hasil uji dimana 
nilai probabilitas (p-value) sebesar 0,046 lebih kecil dari nilai signifikansi 0,05 menunjukkan hasil yang signifikan. Citra bank akan meningkat apabila indikator yang terdapat dalam e-service quality yaitu, information, ease of use, website design, reliability, dan security/privacy berkualitas baik. Seperti akurat jelas, lengkap, mudah dipahami, memiliki tingkat keamanan yang tinggi, dan lain-lain.

\subsection{Pengaruh $E$-trust Terhadap Citra Bank}

Tabel 4 menunjukkan e-trust berpengaruh langsung terhadap Citra Bank. Pengaruh tersebut ditunjukkan dengan nilai koefisien sebesar 0,313. H4 yang menyatakan bahwa menunjukkan e-trust berpengaruh terhadap citra bank dapat diterima. Hal ini dibuktikan melalui hasil uji dimana nilai probabilitas (p-value) sebesar 0,008 lebih kecil dari nilai signifikansi 0,05 menunjukkan hasil yang signifikan. Citra bank akan meningkat apabila indikator yang terdapat dalam e-trust yaitu ability, integrity, dan benevolence meningkat. Seperti peningkatan layanan yang baik, aman, jujur, dan akurat.

\subsection{Pengaruh Citra Bank Terhadap Kepuasan Nasabah}

Tabel 4 menunjukkan citra bank berpengaruh langsung terhadap Kepuasan Nasabah. Pengaruh tersebut ditunjukkan dengan nilai koefisien sebesar 0,129. H5 yang menyatakan bahwa citra bank berpengaruh langsung terhadap kepuasan nasabah dapat diterima. Hal ini dibuktikan melalui hasil uji dimana nilai probabilitas (p-value) sebesar 0,012 lebih kecil dari nilai signifikansi 0,05 menunjukkan hasil yang signifikan. Kepuasan nasabah akan meningkat apabila bank memiliki reputasi yang baik, menjalin hubungan yang baik dengan nasabah, dan lain-lain.

\section{KESIMPULAN}

E-service quality berpengaruh terhadap Kepuasan Nasabah Pengguna BNI Mobile banking. Hal ini menunjukkan bahwa BNI Mobile banking. Sudah mampu memberikan layanan yang baik kepada nasabah.

E-trust berpengaruh terhadap Kepuasan Nasabah Pengguna BNI Mobile banking. Hal ini menunjukkan bahwa transaksi bisnis antara BNI dengan nasabah telah terjadi karena masingmasing pihak saling percaya. e-service quality berpengaruh terhadap citra bank artinya layanan yang baik akan meningkatkan reputasi Bank BNI. e-trust dimana Bank mampu memberikan suatu kepercayaan terhadap nasabahnya dengan memberikan informasi yang akurat, membantu jika terjadi masalah dan bersikap baik.

Citra bank berpengaruh terhadap Kepuasan Nasabah Pengguna BNI Mobile banking. Hal ini menandakan bahwa Bank BNI dianggap berhasil dalam membangun citra banknya dengan memiliki reputasi yang baik, membangun dan memelihara hubungan yang baik, Dengan demikian diharapkan bank dapat mempertahankan kualitas layanan dengan baik, tetap mempertahankan kepercayaan nasabahnya dan tetap menjalin hubungan yang baik dengan nasabah sehingga Bank BNI memiliki reputasi , integritas, kredibilitas dan dikenal dengan baik. 


\section{DAFTAR PUSTAKA}

[1] Windarti, G.A.O. (2012). Pengaruh Kualitas Pelayanan Jasa Terhadap Kepuasan Nasabah pada PT. Bank Negara Indonesia (Persero) Tbk Kantor Cabang Utama (KCU) Palembang. Jurnal Ekonomi dan Informasi Akuntansi (JENIUS), 2(1), 1-20.Moenir, A., \& Yuliyanto, F. Perancangan Sistem Informasi Penggajian Berbasis Web dengan Metode Waterfall pada PT. Sinar Metrindo Perkasa (Simetri). 2017.

[2] Wardhana, A. (2015). Pengaruh Kualitas Layanan Mobile banking (M-Banking) Terhadap Kepuasan Nasabah di Indonesia [Effect of Mobile banking (M-Banking) Service Quality on Customer Satisfaction in Indonesia]. DeReMa (Development Research of Management): Jurnal Manajemen, 10(2), 273-284.

[3] Amijaya, G. R., \& Rahardjo, S. T. (2010). Pengaruh Persepsi Teknologi Informasi, Kemudahan, Resiko Dan Fitur Layanan Terhadap Minat Ulang Nasabah Bank Dalam Menggunakan Internet Banking (Studi Pada Nasabah Bank Bca) (Doctoral dissertation, Perpustakaan FE UNDIP).

[4] Kaswidj Hidayat, R. (2009). Pengaruh kualitas layanan, kualitas produk dan nilai nasabah terhadap kepuasan dan loyalitas nasabah Bank Mandiri. Jurnal Manajemen dan kewirausahaan, 11(1), 59-72. anti, W. Implementasi Fuzzy Inference System Metode Tsukamoto Pada Pengambilan Keputusan Pemberian Kredit Pemilikan Rumah. 2014.

[5] Nawangsari, Sri \& Retno Widiastuti. 2018. Analisis Pengaruh Kualitas Pelayanan, Kepercayaan dan Layanan Mobile banking Terhadap Kepuasan Nasabah Bank (Studi Kasus Pada PT.Bank DKI-Depok). Jurnal Sebatik. Depok: STMIK Widya Cipta Dharma.

[6] Sondakh, C. (2015). Kualitas Layanan, Citra Merek Dan Pengaruhnya Terhadap Kepuasan Nasabah Dan Loyalitas Nasabah Tabungan (Studi Pada Nasabah Taplus BNI Cabang Manado). Jurnal Riset Bisnis dan Manajemen, 3(1).

[7] Saputra, F. I. (2013). Kualitas Layanan, Citra dan Pengaruhnya terhadap Loyalitas melalui Kepuasan Pelanggan (Studi Pada PT Bank Bni 46 Sentra Kredit Kecil
Surabaya). Jurnal Aplikasi Manajemen, 11(3), 445-457.

[8] Nuraini, A. (2014). Pengaruh Citra, Pelayanan, Aksesoris Jasa, Keragaman Produk Dan Nilai Nasabah Terhadap Loyalitas Nasabah (Studi Pada Nasabah BPD DIY Syariah Yogyakarta). Ekbisi, 9(1).

[9] Prisanti, Mega D., Suyadi, Imam dan Arifin, Zainul. 2017. Pengaruh E-Service quality Dan E-Trus Terhadap E-Customer Satisfaction Serta Implikasinya Terhadap Ecustomer Loyalty (Studi Pada Nasabah PT Bank Rakyat Indonesia (Persero) Tbk Kantor Cabang Pembantu Lawang). Journal of Business Studies.

[10] Ihsan, A. N., Wasito, S. E., \& MSIE, P. I. (2019). Pengaruh Kualitas Pelayanan Elektronik Terhadap Kepuasan Pelanggan dan Implikasinya Pada Loyalitas Pelanggan Online Shop JD.ID (Suatu Survey Pada Mahasiswa Fakultas Ekonomi dan Bisnis Universitas Pasundan) (Doctoral dissertation, Perpustakaan Fakultas Ekonomi dan Bisnis Unpas).

[11] Bernita, Y. B. (2019). Analisis Pengaruh Sikap Terhadap Kualitas, Kepuasan, Kepercayaan dan Loyalitas Pada Layanan Perbankan Syariah di Yogyakarta.

[12] Parasuraman et.al. 2000. A Multiple Item Scale for Assesing Electronic Service Quality. Journal of Service Research, Vol. 7, No. X.

[13] Ulum, F., \& Muchtar, R. (2018). Pengaruh E-Service Quality Terhadap E-Customer Satisfaction Website Start-Up Kaosyay. Jurnal Tekno Kompak, 12(2), 68-72.

[14] Saragih, M. G. (2019) Pengaruh E-Service Quality Terhadap E-Loyalty Melalui ESatisfaction (Studi Pada Pelanggan Toko Online Shopee di Kota Medan). Jurnal Mantik, 3(1, Juni), 190-195.

[15] Corritore C., Kracher B., \& Wiedenbeck S. (2003). On-line trust: Concepts, evolving themes, a model. International Journal of Human Computer Studies, 58, 737-58.

[16] Kotler dan Keller. 2009. Manajemen Pemasaran. Jilid I. Edisi ke 13. Jakarta: Erlangga Utama, W. V. Aplikasi Pengolahan Data Alat Tulis Kantor Pada Staff Operasi Komando Daerah Militer II Sriwijaya. 2014. 
[17] Jasfar, Farida. 2005. Manajemen Jasa Pendekatan Terpadu. Bogor: Ghalia Indonesia.

[18] Irawan et.al. 2008. Manajemen Pemasaran Modern. Yogyakarta: Liberty Offset.

[19] David Garson. 2003. Path Analysis. North Carolina State University.

[20] Ghozali, Imam. 2006. Aplikasi Analisis Multivariate Dengan Program SPSS. Cetakan Keempat. Semarang: Badan Penerbit Universitas Diponegoro. 